\title{
Hepatitis C: Could we eradicate this virus?
}

\author{
Fernando Álvarez, M.D. ${ }^{a}$, Miriam L. Cuarterolo, M.D. ${ }^{b}$ and Mirta Ciocca, M.D. ${ }^{c}$
}

\begin{abstract}
Chronic hepatitis $C$ virus infection is a health problem worldwide, both in children and adults. Its spontaneous resolution may occur during early childhood, and then it becomes uncommon. Although most cases are asymptomatic during childhood and adolescence, as adults, patients may progress to cirrhosis and develop complications, including hepatocellular carcinoma. The goal of an effective treatment should be virus elimination, i.e., disease cure. Recently, the emergence of several direct-acting antivirals has enabled a high rate of infection resolution in $97-100 \%$ of cases. To achieve this cost-effective objective, it is critical to raise awareness among pediatricians so that they can detect infected patients and refer them to a pediatric liver specialist for an adequate management.

Key words: hepatitis C, therapy, direct-acting antivirals, cirrhosis.
\end{abstract}

a. Department of Pediatrics, CHUSainte Justine, University of Montreal, Canada.

b. Division of

Hepatology,

Hospital de

Pediatría "Prof. Dr. Juan P. Garrahan". Autonomous City of Buenos Aires, Argentina.

c. Division of Hepatology and Pediatric Liver Transplant, Hospital Alemán, Autonomous City of Buenos Aires, Argentina.

E-mail address: Fernando Álvarez, M.D. fernando.alvarez@ umontreal.ca

Funding:

None.

Conflict of interest: None.

Received: 7-13-2020 Accepted: 10-26-2020 http: / / dx.doi.org/ 10.5546/ aap.2021.eng.208

To cite: Álvarez F, Cuarterolo ML, Ciocca M. Hepatitis C: Could we eradicate this virus? Arch Argent Pediatr 2021;119(3):208-212.

\section{INTRODUCTION}

According to the World Health Organization (WHO), the prevalence of chronic hepatitis $\mathrm{C}$ virus (HCV) infection is approximately 130170 million individuals, i.e., 2-3\% of the world population. ${ }^{1,2}$ Based on Argentina's blood banks, out of 370000 samples, $0.29 \%$ were positive for HCV in 2017..$^{3-8}$

The incidence and prevalence of HCV infection in children is unknown, especially because of the lack of symptoms and a generally benign clinical course. Recent data have reported an estimated world prevalence of $0-15 \%$, corresponding to 3.5-5 million children and adolescents aged 1-19 years. ${ }^{2}$ A strict collection of these data in Argentina, by screening for viral markers in children with risk factors, would facilitate the planning of different strategies to eradicate HCV infection. Disease cure sounded like an utopia until the recent emergence of highly effective treatments with practically no adverse events.

\section{Hepatitis C virus}

$\mathrm{HCV}$ is a ribonucleic acid (RNA) virus of the Flaviviridae family. RNA is expressed as a single polypeptide of approximately 3000 amino acids, which encompass the nucleocapsid protein, two virus surface glycoproteins, and non-structural proteins, which are responsible for viral replication.

There are at least seven HCV genotypes and, due to its high mutability, there are many subtypes. Genotype 1 is prevalent in Argentina, as well as in the rest of America and Europe $(62-71 \%){ }^{1-5}$ Depending on the treatment implemented, the patient's genotype may affect the response.

\section{Modes of transmission}

$\mathrm{HCV}$ may be disseminated from infected mothers to newborn infants or via parenteral, sexual, and intrafamilial transmission, although the latter are uncommon. Personal hygiene items that have been in contact with contaminated blood should always be considered a source of transmission.

Currently, vertical transmission is the most common mode of infection in pediatrics; it is approximately $5 \%$ among positive mothers or $16 \%$ from mother with HCVhuman immunodeficiency virus (HIV) co-infection. The possibility of transmission is directly related to the maternal viral load ( $\mathrm{HCV}$ RNA $>6 \log _{10} \mathrm{IU} / \mathrm{mL}$ ). Antenatal invasive procedures on the fetus should be avoided. A C-section delivery does not reduce the risk 
for vertical transmission. Breastfeeding should be allowed because it is not a mode of $\mathrm{HCV}$ transmission. ${ }^{9-12}$

During adolescence, the possibility of parenteral transmission should be considered as a consequence of sharing personal hygiene items (toothbrushes, razor blades), intravenous drug use or cocaine snorting, tattoos, and piercings. A fundamental element in the fight against $\mathrm{HCV}$ is the detection of infected patients. In all children born from HCV positive mothers, a viral RNA test is indicated in the first months of life or an anti$\mathrm{HCV}$ antibody test after 18 months old. Drugusing adolescents, children with chronic increased serum transaminase levels, and immigrants from endemic areas should be screened for anti-HCV antibodies..$^{1,2,13}$ Currently, transmission from infected blood products is very uncommon due to blood bank controls.

\section{Natural history of hepatitis C}

$\mathrm{HCV}$ infection may be acute in 15-30\% of patients, after an incubation period of 2 weeks to 6 months, and symptoms may last between 2 and 12 weeks. Approximately $15 \%$ of patients may have mild and non-specific symptoms, such as fatigue. In these patients, increased serum transaminase levels should prompt virus screening. Antibodies appear between 6 and 8 weeks after becoming infected. The virus disappears spontaneously in $25 \%$ of cases, whereas the remaining $75 \%$ develops a chronic infection. ${ }^{4,12}$

When the infection is vertically transmitted, the clinical course is similar. Between $20 \%$ and $25 \%$ of children eliminate the virus spontaneously before 4 years old, ${ }^{13}$ and the remaining 75-80\% develop a chronic infection that may last until adulthood. Patients with an increased transaminase level that is five times the normal value manage to eliminate the virus in $66 \%$ of cases. The only factor associated with spontaneous virus elimination is a polymorphism in the IL28B gene, which codes for interferondelta 3. The rs12979860 CT and TT genotypes are unfavorable, whereas the CC genotype is favorable. ${ }^{14}$

The follow-up of patients with chronic hepatitis $\mathrm{C}$ infection showed that some factors are related to a poor prognosis with progression to liver fibrosis, including: age older than 40 years, immunosuppressive therapy, co-infection with hepatitis B virus, and alcohol use. ${ }^{12}$

In children, especially those infected at birth, hepatitis $\mathrm{C}$ has a chronic course which is generally benign, with cirrhosis (1-4 \%) and liver failure occurring as an exception (Figure 1).,14-16 The presence of co-infection with HIV or in patients with cancer and chemotherapy requirement may increase the risk for liver complications.

\section{Treatments for chronic hepatitis $C$ virus infection}

An effective treatment should be aimed at completely eliminating the virus, that is to say, disease cure, because $\mathrm{HCV}$ is a RNA virus that has no possibility of remaining in the cell nucleus episomally or of becoming integrated into the genomic deoxyribonucleic acid (DNA). The final goal of treatment is to achieve a sustained viral

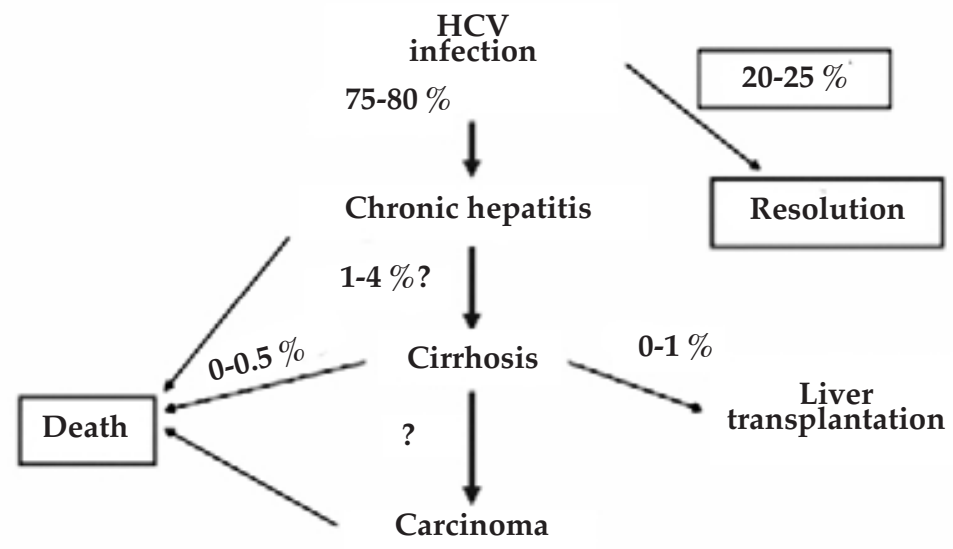


response, defined as the absence of HCV RNA in blood 12 weeks after treatment ending. ${ }^{12}$

Early effective treatments for chronic HCV infection consisted in combined interferon and ribavirin. Later, to reduce the adverse events caused by interferon, slow release pegylated interferon (peg-interferon) was used, which required a single weekly injection. The results of this treatment schedule were encouraging, especially in children with genotypes 2 or 3 , who became HCV negative in $80-93 \%$ of cases. It showed fewer benefits in those with genotype 1 , the most common one in Argentina, and the infection disappeared only in $53 \%$ of cases. ${ }^{11,17,18}$

With the emergence of new direct-acting antivirals (DAAs), which achieve high rates of cure, without resistance mutations, the management of hepatitis $C$ has changed. It is critical to identify asymptomatic children so that they can receive treatment, considering that its high cost is a limitation in many countries. Although DAAs are very effective for virus elimination, re-infections may occur in populations with risk factors. ${ }^{3,12}$

Different combinations, such as sofosbuvir and ledipasvir, velpatasvir or daclatasvir, have been successful in patients younger than 18 years. Sofosbuvir is a nucleotide analogue that strongly inhibits the virus RNA polymerase (NS5B region of the polypeptide). Ledipasvir inhibits the hyperphosphorylation of the NS5A protein, which plays a major role in viral replication. This protein has no enzymatic function. Velpatasvir acts as a defective substrate for the NS5A protein. Likewise, daclatasvir inhibits NS5A interaction with other cellular proteins.

Initially, the sofosbuvir and ledipasvir combination was tested in children aged 1217 years infected with genotype 1 , and it was successful in $98 \%$ of patients. Since then, the combination has been approved for its use in this age group. ${ }^{19}$ Murray et al. and Schwarz et al., confirmed virus elimination in $97-99 \%$ of cases after the administration of the sofosbuvir and ledipasvir combination to children aged 6-12 years and 3-6 years. ${ }^{17-21}$

Patients who were previously treated with peg-interferon and ribavirin and those with cirrhosis (aged 3-12 years) received this combination for 12 weeks if they were infected with genotype 2 or for 24 weeks if they had genotype 3 . In both groups, a positive response of $98 \%$ was observed. The IL28B gene did not affect treatment response. In children between
3 and 12 years, treatment with sofosbuvir and ribavirin led to virus elimination, similarly to the treatments mentioned before. ${ }^{22}$ The sofosbuvir and daclatasvir combination administered to adolescents for 12 weeks led to infection resolution in all patients. In subsequent studies, treatment duration was reduced to 8 weeks and results were the same..$^{23,24}$

Recently, a new combination was administered to a population of adolescents, which was again $100 \%$ effective after 8 weeks of treatment. Such combination was glecaprevir and pibrentasvir. The former is a protease NS3-4A inhibitor, and the latter, a NS5A protein inhibitor. Patients who had genotypes 1a, 1b, 2, 3, and 4 were treated with this protocol. ${ }^{25,26}$

Other very important aspect of using these drugs is the absence of serious adverse events. It is worth noting that both the peginterferon and ribavirin combination and that with the nucleotide analogues described here, treatment response is not correlated with serum transaminase levels. The availability of treatments mentioned here (Table 1), which are highlyeffective, regardless of fibrosis stage, allows their administration without the requirement of a previous liver biopsy.

Chronic hepatitis $\mathrm{C}$ in children, although it is usually asymptomatic and rarely progresses to cirrhosis before 18 years old, is associated with a poor quality of life in both patients and their families, who have to live with the stigma of the disease.

Recently, it has been demonstrated that HCV treatment in young children is cost-effective compared to its indication in adults. ${ }^{27,28}$

The United States Food and Drug Administration (FDA), a government agency responsible for regulating foods and drugs, and the European Medicines Agency (EMA) approved, for patients aged 12-18 years (or for those who with a weight of $35 \mathrm{~kg}$ or more), a fixed ledipasvir/sofosbuvir dose for those infected with genotypes 1 and 4-6 or the sofosbuvir and ribavirin combination for those with genotypes 2 or 3 .

The National Ministry of Health of Argentina, with the support of hepatologists, should make every necessary effort to achieve the early diagnosis of $\mathrm{HCV}$ cases at a national level. The National Drug, Food and Technology Administration of Argentina (Administración Nacional de Medicamentos, Alimentos y Tecnología Médica, ANMAT) may help with the approval, in our country, of the drugs which 
TABLE 1. Treatment of pediatric patients with con chronic HCV infection

\begin{tabular}{|c|c|c|c|c|}
\hline Treatment & Age & Duration & Genotype/elimination & Reference/year \\
\hline Peg-interferon/ribavirin & 3-17 years & $24-48$ weeks & $\begin{array}{c}\text { Genotype 1: } 53 \% \\
\text { Genotypes 2, 3, 4: 80-93\% }\end{array}$ & Wirth et al. 2010 \\
\hline Sofosbuvir/ledipasvir & $>12-17$ years & 12 weeks & All genotypes: $98 \%$ & Balistreri et al. 2017 \\
\hline Sofosbuvir/ledipasvir & $6-12$ years & 12 weeks & All genotypes: $100 \%$ & Murray et al. 2018 \\
\hline Sofosbuvir/daclatasvir & $12-17$ years & 12 weeks & Genotype 4: $100 \%$ & Yakoot et al. 2018 \\
\hline Sofosbuvir/daclatasvir & $12-17$ years & 8 weeks & $100 \%$ & El-Shabrawi et al. 2018 \\
\hline Glecaprevir/pibrentasvir & $12-17$ years & 12 weeks & All genotypes: $100 \%$ & Jonas et al. 2020 \\
\hline Sofosbuvir/ ribavirin & $3-12$ years & 12-24 weeks & $2-3 / 98 \%$ & Rosenthal et al. 2020 \\
\hline Sofosbuvir/ledipasvir & 3-6 years & 12 weeks & $1-4 / 97 \%$ & Schwarz et al. 2020 \\
\hline
\end{tabular}

have proven effective in the treatment of $\mathrm{HCV}$ infection. A collective effort may lead to virus eradication.

\section{CONCLUSIONS}

The eradication of chronic HCV infection calls for the detection of infected people and treatment availability. It is very important to note that treatment with nucleotide analogues is effective in patients with normal or increased serum transaminases. The presence of liver inflammation and its severity do not affect the response to these treatments. Therefore, they may be initiated as soon as diagnosis is confirmed, with a high level of effectiveness in infections from any known genotype.

The cost of the treatments described here is extremely high on any health care system. However, they are cost-effective in adults; for this reason, based on the same analysis, they will be even more so in pediatric patients. These reasons are grounded on the reduced number of followup years, reduced lab test and $\mathrm{x}$-ray costs, a better quality of life with the complete and permanent virus eradication, and the prevention of cirrhosis, hepatocellular carcinoma, and, eventually, liver transplantation requirement.

In other terms, each health care system should implement the necessary conditions so that children with chronic HCV infection can receive an effective treatment as of 6 years old because, from that moment on, vertical spontaneous virus elimination in infected patients is rare. HCV eradication in Argentina calls for a collective effort.

\section{REFERENCES}

1. Indolfi G, Easterbrook P, Dusheiko G, El-Sayed MH, et al.
Hepatitis $C$ virus infection in children and adolescents. Lancet Gastroenterol Hepatol. 2019; 4(6):477-87.

2. Indolfi G, Hierro L, Dezsofi A, Jahnel J, et al. Treatment of Chronic Hepatitis C Virus Infection in Children: A Position Paper by the Hepatology Committee of European Society of Paediatric Gastroenterology, Hepatology and Nutrition. J Pediatr Gastroenterol Nutr. 2018; 66(3):505-15.

3. Gower E, Estes C, Blach S, Razavi-Shearer K, et al. Global epidemiology and genotype distribution of the hepatitis C virus infection. J Hepatol. 2014; 61(1 Suppl):S45-57.

4. Hanafiah KM, Groeger J, Flaxman AD, Wiersma ST. Global Epidemiology of Hepatitis C Virus Infection: New Estimates of Age-Specific Antibody to HCV Seroprevalence. Hepatology. 2013; 57(4):1333-42.

5. KershenobichD, RazaviHA, Sánchez-AvilaJF, BessoneF, et al. Trends and projections of hepatitis $C$ virus epidemiology in Latin America. Liver Int. 2011; 31(Suppl 2): 18-29.

6. Ridruejo E, Fainbom H, Villamil Giraldo A. Cribado, diagnóstico y tratamiento de la hepatitis $C$ en la práctica clínica. Medicina (B. Aires). 2016; 76(6):390-8.

7. Boletín sobre las Hepatitis Virales en la Argentina $\mathrm{N}^{\circ} 1$. Octubre de 2019. [Accessed on: October $26^{\text {th }}, 2020$ ]. Available at:https: / / bancos.salud.gob.ar/recurso/boletin-sobre-lashepatitis-virales-en-la-argentina-ndeg1.

8. Argentina, Ministerio de Salud. Salud presentó el primer boletín epidemiológico sobre las Hepatitis Virales en Argentina. [Accessed on: October 26 ${ }^{\text {th }}, 2020$ ]. Available at: https: / / www.argentina.gob.ar/noticias/salud-presentoel-primer-boletin-epidemiologico-sobre-las-hepatitisvirales-en-argentina.

9. Delotte J, Barjoan EM, Berrebi A, Laffont M, et al. Obstetric management does not influence vertical transmission of HCV infection: results of the ALHICE group study.JMatern Fetal Neonatal Med. 2014; 27(7):664-70.

10. Tovo PA, Calitri C, Scolfaro C, Gabiano C, et al. Vertically acquired hepatitis $C$ virus infection: Correlates of transmission and disease progression. World J Gastroenterol. 2016; 22(4):1382-92.

11. Benova L, Mohamoud YA, Calvert C, Abu-Raddad LJ. Vertical transmission of hepatitis $C$ virus: systematic review and meta-analysis. Clin Infect Dis. 2014; 59(6):765-73.

12. Resti M, Jara P, Hierro L, Azzari C, et al. Clinical Features and Progression of Perinatally Acquired Hepatitis C Virus Infection. J Med Virol. 2003; 70(3):373-7.

13. Hajarizadeh B, Grebely J, Dore GJ. Epidemiology and natural history of HCV infection. Nat Rev Gastroenterol Hepatol. 2013; 10(9):553-62. 
14. IndolfiG,MangoneG, Calvo PL, BartoliniE, etal.Interleukin 28B rs12979860 Single-Nucleotide Polymorphism Predicts Spontaneous Clearance of Hepatitis C Virus in Children. J Pediat Gastroenterol Nutr. 2014; 58(5):666-8.

15. Mohan P, Barton BA, Narkewicz MR, Molleston JP, et al. Evaluating Progression of Liver Disease From Repeat Liver Biopsies in Children With Chronic Hepatitis C: A Retrospective Study. Hepatology. 2013; 58(5):1580-6.

16. Goodman ZD, Makhlouf HR. Liu L, Balistreri W, et al. Pathology of Chronic Hepatitis C in Children: Liver Biopsy Findings in the Peds-C Trial. Hepatology. 2008; 47(3):836-43.

17. Schwarz KB, Gonzalez-Peralta RP, Murray KF, Molleston $\mathrm{JP}$, et al. The Combination of Ribavirin and Peginterferon Is Superior to Peginterferon and Placebo for Children and Adolescents With Chronic Hepatitis C. Gastroenterology. 2011; 140(2):450-8.

18. Wirth S, Ribes-Konincks C, Calzado MA, Bortolotti F, et al. High sustained virologic response rate in children with chronic hepatitis $C$ receiving peginterferonalfa $2 b$ plus ribavirin. J Hepatol. 2010; 52(4):501-7.

19. Abdel-Hady M, Bansal S, Davison SM, Brown M, et al. Treatment of chronic viral hepatitis $C$ in children and adolescents:UKexperience. Arch Dis Child.2014;99(6):50510.

20. Balistreri W, Murray KF, Rosenthal Ph, Bansal S, et al. The Safety and Effectiveness of Ledipasvir-Sofosbuvir in Adolescents 12-17 Years Old With Hepatitis C Virus Genotype 1 Infection. Hepatology. 2017; 66(2):371-8.

21. Murray KF, Balistreri W, BansalS, WhitworthS, et al. Safety and Efficacy of Ledipasvir-Sofosbuvir With or Without
Ribavirin for Chronic Hepatitis C in Children Ages 6-11. Hepatology. 2018; 68(6):2158-66.

22. Schwarz KB, Rosenthal PH, Murray KF, Honegger JR, et al. Ledipasvir-Sofosbuvir for 12 Weeks in Children 3 to $<6$ Years Old With Chronic hepatitis C. Hepatology. 2020; 71(2):422-30.

23. Rosenthal PH, Schwarz KB, Gonzalez-Peralta RP, Lin ChH, et al. Sofosbuvir and Ribavirin Therapy for Children Aged 3 to $<12$ Years With Hepatitis C Virus Genotype 2 or 3 Infection. Hepatology. 2020; 71(1):31-43.

24. Yakoot M, El-Shabrawi MH, AbdElgawad MM, Mahfouz AA, et al. Dual Sofosbuvir/Daclatasvir Therapy in Adolescent Patients With Chronic Hepatitis C Infection. J Pediatr Gastroenterol Nutr. 2018; 67(1):86-9.

25. El-Shabrawi MH, Abdo AM, El-Khayat HR, Yakoot M. Shortened 8 weeks course of dual sofosbuvir/daclatasvir therapy in adolescent patients, with chronic hepatitis C infection. J Pediatr Gastroenterol Nutr. 2018; 66(3):425-7.

26. Jonas MM, Squires RH, Rhee SM, Lin CW, et al. Pharmacokinetics, Safety, and Efficacy of Glecaprevir/ Pibrentasvirin Adolescents With Chronic Hepatitis CVirus: Part 1 of the DORA Study. Hepatology. 2020; 71(2):456-62.

27. Greenaway E, Haines A, Ling S, Krahn M. Treatment of Chronic Hepatitis C in Young Children Reduces Adverse Outcomes and Is Cost-Effective Compared with Deferring Treatment to Adulthood. J Pediatr. 2020; Sept 2:1-8. [In press]

28. Rodríguez-Baez N.Hepatitis Cin Young Children:To Treat or Not to Treat $\square$ Is It Cost-Effective? J Pediatr. 2020; Oct 16: 1-9. [In press] 